\title{
28 Research Square \\ Cost-Effectiveness of Stroke Unit Compared With Routine Treatment For Stroke Patients In Iran
}

\author{
Mohammad Tasavon Gholamhoseini \\ Kerman University of Medical Sciences \\ Reza Goudarzi ( $\sim$ rgoudarzi@kmu.ac.ir) \\ Kerman University of Medical Sciences https://orcid.org/0000-0003-4399-3498 \\ Mahdiye Zarein \\ Yazd University of Medical Science \\ Mohammadreza Amiresmaili \\ Kerman University of Medical Sciences \\ Masoud Mehrpour \\ Iran University of Medical Sciences
}

\section{Research}

Keywords: Cost-Effectiveness, Stroke Unit, Routine Treatment, Stroke Patient, Iran.

Posted Date: November 2nd, 2021

DOI: https://doi.org/10.21203/rs.3.rs-180729/v2

License: (c) (1) This work is licensed under a Creative Commons Attribution 4.0 International License. Read Full License 


\section{Abstract}

Background: Two approaches including stroke unit and routine treatment, are used to address stroke patients. Although stroke unit is a new intervention in Iran and its effectiveness has been proven, but there is little information on its costs. It is necessary to utilize the results of the studies of economic evaluation in order to choose the better treatment option between two alternatives. Due to the lack of studies in this field in Iran, the current study was conducted to assess the cost-effectiveness of stroke unit and routine treatment.

Methods: A Markov model incorporating three health states of independent, dependent and death for a time horizon of 10 years with a 3-month cycle length was applied. Direct medical and non-medical costs, including pharmaceutical and hospital expenses, were calculated based on 2018 data from a health system perspective. Quality-adjusted life-years (QALYs) were taken as the outcome measure. The analysis of cost-effectiveness and sensitivity for uncertain parameters was carried out using TreeAge 2020.

Results: The stroke unit had more costs and QALYs gain in comparison with routine treatment, and it was cost-effective with an ICER of 551 PPP dollars per QALY. Probabilistic sensitivity analysis showed that stroke unit cost-effectiveness probability is 78 percent, in the threshold of willingness to pay three times GDP per capita.

Conclusion: Incremental cost-effectiveness ratio of stroke unit is far less than the threshold of willingness to pay, indicating the strategy is cost-effective. Therefore, implementing stroke unit in Iran health system leads to optimal use of resources.

\section{Background}

Stroke is one of the leading causes of morbidity and the second cause of mortality in the world. Stroke occur for fifteen million people annually and according to the statistics, two-third of them survive but suffer from severe and long-term morbidities for the rest of their lives. Most of stroke happens in low and middle-income countries (1-3).

Different numbers on prevalence and incidence of stroke in Iran are reported $(4,5)$. Overall, it can be stated that the incidence of the first-ever stroke in Iran is 139 cases per 10000 people (6). Studies have also shown that the age of chronic stroke in Iran has been lower than the average number of other countries, but they lead to more mortalities $(5,7)$.

Stroke, due to many side effects, increases the costs of health system. The results of a study in England showed that the total cost of patients with chronic stroke in the first five years after reception in the hospital was 3.60 billion pounds (8). Also, this cost was 6.855 billion dollars in South Korea (9), 3.6 billion dollars in Canada and 34 billion dollars in the United States of America (10). 
One of the interventions which leads to decrease in morbidities after stroke as confirmed in many countries is stroke unit (SU) in which a team consisting of multiple experts in managing stroke carry out treatments at proper time (11-13). The studies show that stroke unit has been successful and could decrease mortality by up to 20 percent $(14,15)$.

In Iran like other developing countries patients with stroke might under or over utilize health care services. On the one hand, due to shortage of specialized centers for stroke care in Iran, most of patients with stroke are hospitalized in general or non-related wards, facing higher rates of morbidity and mortality. On the other hand, a considerable percentage of these patients are hospitalized in ICUs, with many of them do not need all ICU services, and they occupy the beds (16).

Few studies have investigated the cost-effectiveness of stroke unit. For instance, some studies have been done in the UK (17), France $(18)$, and Australia $(14,19)$ revealing that stroke unit intervention is costeffective.

Given the high costs of treatment and rehabilitation of stroke patients and the importance of costeffective interventions for health system policymakers and the limited generalizability and comparability of economic evaluation studies from one place to another due to differences in conditions and the health systems of the countries (20). Hence this study aimed to determine the cost-effectiveness of stroke unit compared to routine treatment (RT) in Iran.

\section{Materials}

\section{Study Design}

This was a cost-effectiveness study that compared two strategies of stroke unit and routine treatment for treating patients with stroke in 10-year time horizon from health system perspective. Data of 231 and 205 stroke patients who received stroke unit and routine treatment strategies, respectively, were collected from two Iranian hospitals from June 2016 to June 2017. Costs and outcomes were discounted by $6 \%$ and $3 \%$, respectively (21).

\section{Strategies}

In this study, two strategies, stroke unit, and routine treatment, were compared. A stroke unit comprises a multidisciplinary team of clinicians and nursing staff that cares for stroke patients exclusively. In Iran, the only Firoozgar hospital in Tehran had a stroke unit to care for stroke patients. Therefore, we used the data of this hospital for the stroke unit strategy.

A routine treatment is a section of the hospital providing medical care without the usual multidisciplinary input. The Shafa Hospital in Kerman has a general medical facility, and we used the data from this hospital.

\section{Model structure}


Markov model, including three health states of Independent, Dependent, and Death with 3-month cycles, was used to evaluate and compare costs and long-term consequences (Figure 1). Health states were driven from stroke patients score on modified-Rankin-Scale (mRS). According to this scale, stroke patients fall into three groups: Independent $(m R S=0,1,2)$, Dependent $(m R S=3,4,5)$ and Death $(m R S=$ 6). Patients in an Independent state are in good health and carry out their daily activities without the help of other people; patients in a Dependent state rely on others for their daily activities, and ultimately Death state. In this model, Recurrent Stroke is not considered due to insufficient data.

\section{Costs}

Costs included direct medical and non-medical costs. Direct medical costs covered medication costs, physician visits, consultation, nursing services, diagnostic tests, therapists and so on. Direct non-medical cost addressed hospitalization costs such as meals on wheels, homemaking services and so on. These costs were calculated based on the patient's medical record for different health states (Table 1). The average annual exchange rate of Iranian Rials (IR) to US dollars in 2021 was 42,000 IR (22). To convert the costs in local currency units to US dollars, we multiplied the IR exchange rate by the 2018 purchasing power parity (PPP) conversion factor (23), which was 146,681 Rials to 1 PPP dollar in 2018.

\section{Outcome}

Quality-adjusted Life Years (QALY), a combination of length and quality of life was used as the outcome measure. The quality of life, utility scores for each Markov model state were extracted from the study of Sandercock et al (24). It should be noted that since alterplase was used in both strategies, it did not vary in terms of utilities, and thus utilities were assumed to be the same for both strategies.

\section{Probabilities}

The transition probability between different states was extracted from previous studies (24-26) (Table 1). The patient in the Independent state is more likely to remain in his / her state and is less likely to fall into the Dependent and Death states. The patient in the Dependent state is also more likely to remain in his/her state. Stroke unit reduced the relative risk of death by $41 \%$ (27). Thus, the stroke unit strategy decreases the risk of transmission to death compared to the RT strategy. 
Table 1

Model Parameters and Range of Values for Sensitivity Analysis: Transition probabilities, Utility Values,

Efficacy and Cost Inputs

\begin{tabular}{|c|c|c|c|c|c|c|}
\hline \multirow[t]{2}{*}{ Parameter } & \multirow{2}{*}{$\begin{array}{l}\text { Base } \\
\text { case } \\
\text { value }\end{array}$} & \multirow[t]{2}{*}{ Distribution } & \multicolumn{2}{|c|}{$\begin{array}{l}\text { Distribution } \\
\text { parameters }\end{array}$} & \multirow[t]{2}{*}{ Range } & \multirow[t]{2}{*}{ References } \\
\hline & & & a & $\beta$ & & \\
\hline \multicolumn{7}{|l|}{ Transition probabilities } \\
\hline $\begin{array}{l}\text { Independence to } \\
\text { Independence }\end{array}$ & 0.8750 & & & & $\begin{array}{l}0.77- \\
0.89\end{array}$ & $(24-26)$ \\
\hline $\begin{array}{l}\text { Independence to } \\
\text { Dependence }\end{array}$ & 0.1111 & & & & $\begin{array}{l}0.03- \\
0.18\end{array}$ & $(24-26)$ \\
\hline $\begin{array}{l}\text { Dependence to } \\
\text { Independence }\end{array}$ & 0.0938 & & & & $\begin{array}{l}0.07- \\
0.11\end{array}$ & $(24-26)$ \\
\hline $\begin{array}{l}\text { Dependence to } \\
\text { Dependence }\end{array}$ & 0.7407 & & & & $\begin{array}{l}0.65- \\
0.81\end{array}$ & $(24-26)$ \\
\hline \multicolumn{7}{|l|}{ Utility values } \\
\hline Independence & 0.74 & Beta & 683 & 3021 & $\begin{array}{l}0.69- \\
0.79\end{array}$ & (24) \\
\hline Dependence & 0.38 & Beta & 60 & 590 & $\begin{array}{l}0.29- \\
0.47\end{array}$ & (24) \\
\hline \multicolumn{7}{|l|}{ Efficacy } \\
\hline $\begin{array}{l}\text { Relative risk (RR) of death } \\
\text { in Stroke Unit }\end{array}$ & 0.59 & Beta & 11.843 & 8.230 & $\begin{array}{l}0.42- \\
0.84\end{array}$ & $(27)$ \\
\hline \multicolumn{7}{|l|}{ Costs (PPP \$) } \\
\hline Independent SU & 923 & Gamma & & & $\begin{array}{l}693- \\
1154\end{array}$ & \multirow{3}{*}{$\begin{array}{l}\text { Data from } \\
\text { Firoozgar } \\
\text { hospital }\end{array}$} \\
\hline Dependent SU & 1121 & Gamma & & & $\begin{array}{l}841- \\
1402\end{array}$ & \\
\hline Dead SU & 1445 & Gamma & & & $\begin{array}{l}1084- \\
1806\end{array}$ & \\
\hline Independent CC & 328 & Gamma & & & $\begin{array}{l}246- \\
410\end{array}$ & \multirow{3}{*}{$\begin{array}{l}\text { Data from } \\
\text { Shafa } \\
\text { Hospital }\end{array}$} \\
\hline Dependent CC & 569 & Gamma & & & $\begin{array}{l}427- \\
711\end{array}$ & \\
\hline Dead CC & 1296 & Gamma & & & $\begin{array}{l}972- \\
1620\end{array}$ & \\
\hline
\end{tabular}

\section{Cost-effectiveness analysis}


Incremental cost-effectiveness ratio (ICER) was measured using the following formula in TreeAge 2020:

$$
I C E R=\frac{\operatorname{Cost}(S U)-\operatorname{Cost}(R T)}{Q A L Y(S U)-Q A L Y(R T)}
$$

\section{Sensitivity analysis}

Deterministic and probabilistic sensitivity analysis were used to investigate the effect of uncertain parameters of the model including cost per health state, transition probabilities, utilities and discount rates at a 95\% confidence interval. Probabilistic sensitivity analysis (PSA) using Monte Carlo simulation was carried out 5000 iterations and the effect of the parameters on the outcome of cost-effectiveness was investigated. The threshold of willingness to pay was set three times of GDP per capita, according to the recommendation of the World Health Organization (28), which was 4767 PPP dollars/QALY for Iran in 2018 (29).

\section{Results}

The results showed that most stroke unit patients were male (65\%), while most treated by standard approach were female (51\%). The mean age of the patients was 63 years and 68 years for stroke unit and routine treatment, respectively.

\section{Base case result}

The base case results are shown in Table 2. Stoke unit for stroke patients in 2-year time horizon has a cost of 8,473 PPP \$ for 3.38 QALY. The use of routine treatment for stroke patients has a cost of 5,793 PPP \$ for 2.84 QALY. The ICER of stroke unit with routine treatment was estimated 4,920 PPP \$/QALY gained. The results show that ICER of stroke unit is more than GDP per capita, indicating that studied strategy is not cost-effective compared to the routine treatment.

In a 5-year time horizon, the stroke unit was both more costly and more effective than routine treatment. The ICER of stroke unit was 1,095 PPP \$/QALY gained and was cost-effective.

Over a 10-year time horizon, the stroke unit was both more costly and more effective than routine treatment, and the ICER was 551 PPP \$/QALY gained, so the stroke unit strategy was cost-effective for treating stroke patients. 
Table 2

Base case results: Cost, Effectiveness and Incremental cost-effectiveness ratio in different time horizon

\begin{tabular}{|c|c|c|c|c|c|c|c|}
\hline Strategies & $\begin{array}{l}\text { Time } \\
\text { horizon }\end{array}$ & QALYs & $\begin{array}{l}\text { Incremental } \\
\text { QALYs }\end{array}$ & $\begin{array}{l}\text { Costs(PPP } \\
\$ \text { \$) }\end{array}$ & $\begin{array}{l}\text { Incremental } \\
\text { Costs(PPP \$) }\end{array}$ & ICER & ACER \\
\hline $\begin{array}{l}\text { Routine } \\
\text { treatment }\end{array}$ & 2 & 2.84 & - & 5,793 & - & - & 2,041 \\
\hline Stroke Unit & & 3.38 & 0.54 & 8,473 & 2,680 & 4,920 & 2,504 \\
\hline $\begin{array}{l}\text { Routine } \\
\text { treatment }\end{array}$ & 5 & 3.87 & - & 17,212 & - & - & 4,445 \\
\hline Stroke Unit & & 6.78 & 2.91 & 20,394 & 3,182 & 1,095 & 3,008 \\
\hline $\begin{array}{l}\text { Routine } \\
\text { treatment }\end{array}$ & 10 & 4.08 & - & 33,794 & - & - & 8,288 \\
\hline Stroke Unit & & 10.18 & 6.10 & 37,159 & 3,365 & 551 & 3,650 \\
\hline
\end{tabular}

\section{Sensitivity analysis}

The results of a deterministic sensitivity analysis (DSA), as shown on a tornado diagram, reveal that changing any of the parameters alone had no influence on the cost-effectiveness results Finally, this diagram demonstrates that cost of death state in stroke unit strategy is the most important parameters affecting ICER (Figure 2).

Figure 3 illustrates the scatter plot of the uncertainty pertaining to incremental costs and effects expected. The cost-effectiveness acceptability plane consists of four separated areas each having different cost and effect. Strategies placed in northeast (NE) area improve effects with higher costs; those in southeast (SE) improve effects and save costs; those in southwest (SW) reduce effects and save costs; and those in northwest (NW) decrease effects and increase costs. Dominant strategies are always located in SE; deciding to prefer strategies in NE and SW depends on the willingness to pay for incremental increases in QALYs. As shown in Figure 4, most trial points are in the NE (40\%) and SE (38\%) areas; hence the cost-effectiveness probability is $78 \%$.

Moreover, as illustrated in Figure 4, the cost-effectiveness acceptability curve shows that the probability of cost-effectiveness of stroke unit strategy in threshold of willingness to pay is 4767 PPP dollars/QALY which equals $78 \%$.

\section{Discussion}

This study sought a cost-effective strategy for the management of stroke. Findings showed that treating stroke patients in the stroke unit was not cost-effective in the short term; however, it was cost-effective in the long term, compared to routine treatment. In fact, SU had higher costs and QALYs than RT in the long run, and ICER of 551 PPP dollars per QALY was less than the 4,767 PPP dollars per QALY threshold of willingness to pay. 
The cost of stroke unit intervention for 10 years time horizon was 37,159 PPP dollars; this cost was $£ 46,900$ in a UK study in $2008,15,383$ Australian dollars in an Australian study for 28 weeks; $£ 34,638$ in French 5-year intervention study. After adjusting the costs of above-mentioned studies for time horizon, year of the study, and exchange rate, it can be concluded that SU in Iran is more expensive. One probable explanation for this might be relative higher cost of equipping stroke units regarding the fact the most of them should be imported from other countries.

The incremental cost-effectiveness ratio was 551 PPP dollars per QALY, which is low than the threshold of willingness to pay (three times of GDP per capita), and starting specialized stroke units is worth spending. The findings of other studies are consistent with the present study. For example, a study in the UK showed that the ICER of stroke care unit followed by Early Supported Discharge was 11,615 pounds/QALY, which was cost-effective compared to the UK WTP threshold, which is $£ 30,000 / Q A L Y$ (17). Another study in Australia also showed that the ICER of stroke care units compared to conventional care varied from $\$ 9,867$ to $\$ 16,372$ (depending on side effects) per patient (14). In a study in France, the ICER of stroke care units compared to conventional care was $€ 1,359$ per QALY, which was cost-effective compared to the France WTP threshold of $€ 53,400 /$ QALY (18).

The DSA showed that the most important parameter affecting ICER was the cost of death state in stroke unit strategy. Similarly, a study by Launois et al. showed that even if the costs of stroke units are 10 times higher than the current cost of conventional care, the cost-effectiveness results would not change.

The findings of the probabilistic sensitivity analysis showed that for the threshold of willingness to pay three times of GDP per capita, stroke unit strategy is more likely (78\%) to be cost-effective. In this regard, Saka et al. showed that a stroke care unit with Early Supported Discharge is $97 \%$ likely to be costeffective (17).

There are very few stroke care units equipped with trained medical and nursing teams, specialized equipment, and facilities in Iran. It is very costly to set up a stroke center, and it may seem at first glance that the Stroke unit is not affordable, but in the long run, they prove their value for cost spent. It has been shown that the stroke unit lead to less mortality, institutionalized care, and dependence than conventional care (1). Therefore, it is recommended that policymakers pay special attention to the development of stroke units to treat stroke patients in Iran and consider it as a priority.

This study faced some limitations. First, efficacy, utility values and transition probabilities were obtained from studies performed in other countries due to the lack of Iranian data. Second, cost data were derived from two hospitals that differed geographically. This is because lack of hospitals that provide a stroke unit.

\section{Conclusion}

The results of this study showed that stroke unit is cost-effective in the long-term in Iran. Stroke patients require a stroke unit with multidisciplinary expertise. It can be expected to reduce the cost arising from the 
side effects in the long run by implementing a stroke unit. The results of this study may be generalizable to other regions that are similar to Iran in terms of economic indicators.

\section{Abbreviations}

SU: Stroke unit; RT: Routine treatment; QALYs: Quality-adjusted life-years; ICER: Incremental costeffectiveness ratio; PSA: Probabilistic sensitivity analysis; DSA: Deterministic sensitivity analysis; WTP: willingness to pay

\section{Declarations}

\section{Ethics approval and consent to participate}

This study was approved by the Ethics Committee of Kerman University of Medical Sciences (No. IR.KMU.REC.1398.619).

\section{Consent for publication}

Not applicable.

\section{Availability of data and materials}

The dataset used during the current study is available from the corresponding author, RG, on reasonable request.

\section{Competing interests}

The authors declare that they have no competing interests.

\section{Funding}

No funding to declare.

\section{Authors' contributions}

MTG, RG, MA, and MZ contributed to the conception and design. MZ and MM conducted the data collection and contributed to acquisition. MTG performed the cost-effectiveness analysis. All authors contributed to the interpretation of the results. MTG drafted the manuscript. All authors revisited the manuscript critically. All authors read and approved the final manuscript.

\section{Acknowledgments}

We thank all staff at Shafa and Firozgar hospitals for their cooperation and assistance in collecting data. 


\section{References}

1. Benjamin EJ, Muntner P, Bittencourt MS. Heart disease and stroke statistics-2019 update: a report from the American Heart Association. Circulation. 2019;139(10):e56-28. doi:10.1161/CIR.0000000000000659.

2. Donkor ES. Stroke in the 21 (st) Century: A Snapshot of the Burden, Epidemiology, and Quality of Life. Stroke Res Treat. 2018:3238165. doi:10.1155/2018/3238165.

3. Kuklina EV, Tong X, George MG, Bansil P. Epidemiology and prevention of stroke: a worldwide perspective. Expert Rev Neurother. 2012;12(2):199-208. doi:10.1586/ern.11.99.

4. Habibi-koolaee M, Shahmoradi L, Niakan Kalhori SR, Ghannadan H, Younesi E. Prevalence of Stroke Risk Factors and Their Distribution Based on Stroke Subtypes in Gorgan: A Retrospective HospitalBased Study-2015-2016. Neurology Research International. 2018:7. doi:10.1155/2018/2709654.

5. Azarpazhooh MR, Etemadi MM, Donnan GA, Mokhber N, Majdi MR, Ghayour-Mobarhan M, et al. Excessive incidence of stroke in Iran: evidence from the Mashhad Stroke Incidence Study (MSIS), a population-based study of stroke in the Middle East. Stroke. 2010;41(1):e3-10. doi:10.1161/strokeaha.109.559708.

6. Ghandehari K. Epidemiology of Stroke in Iran. Galen Medical Journal. 2016;5(1):7.

7. Borhani-Haghighi A, Safari R, Heydari ST, Soleimani F, Sharifian M, Yektaparast Kashkuli S, et al. Hospital mortality associated with stroke in southern iran. Iran J Med Sci. 2013;38(4):314-20.

8. Xu XM, Vestesson E, Paley L, Desikan A, Wonderling D, Hoffman A, et al. The economic burden of stroke care in England, Wales and Northern Ireland: Using a national stroke register to estimate and report patient-level health economic outcomes in stroke. European stroke journal. 2018;3(1):82-91. doi:10.1177/2396987317746516.

9. Cha Y-J. The Economic Burden of Stroke Based on South Korea's National Health Insurance Claims Database. Int J Health Policy Manag. 2018;7(10):904-9. doi:10.15171/ijhpm.2018.42.

10. Lapchak PA, Zhang JH. The High Cost of Stroke and Stroke Cytoprotection Research. Translational Stroke Research. 2017;8(4):307-17. doi:10.1007/s12975-016-0518-y.

11. Trialists'Collaboration SU. Collaborative systematic review of the randomised trials of organised inpatient (stroke unit) care after stroke. Bmj. 1997;314(7088):1151-9.

12. Chan DK, Cordato D, O'Rourke F, Chan DL, Pollack M, Middleton S, et al. Comprehensive stroke units: a review of comparative evidence and experience. International journal of stroke: official journal of the International Stroke Society. 2013;8(4):260-4. doi:10.1111/j.1747-4949.2012.00850.x.

13. Stroke Unit Trialists Collaboration. Organised inpatient (stroke unit) care for stroke. Cochrane Database of Systematic Reviews. 2013(9). doi:10.1002/14651858.CD000197.pub3.

14. Moodie M, Cadilhac D, Pearce D, Mihalopoulos C, Carter R, Davis S, et al. Economic evaluation of Australian stroke services: a prospective, multicenter study comparing dedicated stroke units with other care modalities. Stroke. 2006;37(11):2790-5. doi:10.1161/01.STR.0000245083.97460.e1. 
15. Langhorne P, Williams BO, Gilchrist W, Howie K. Do stroke units save lives? The Lancet. 1993;342(8868):395-8. doi:10.1016/0140-6736(93)92813-9.

16. Vice- Chancellor's Office in Treatment Affairs. Management of treatment of acute stroke 2013 [May 31. 2021, Available from: http://ta.mui.ac.ir/sites/ta.mui.ac.ir/files/pdf/shenasnameh-1.pdf].

17. Saka O, Serra V, Samyshkin Y, McGuire A, Wolfe CC. Cost-effectiveness of stroke unit care followed by early supported discharge. Stroke. 2009;40(1):24-9. doi:10.1161/strokeaha.108.518043.

18. Launois R, Giroud M, Megnigbeto AC, Le Lay K, Presente G, Mahagne MH, et al. Estimating the costeffectiveness of stroke units in France compared with conventional care. Stroke. 2004;35(3):770-5. doi:10.1161/01.str.0000117574.19517.80.

19. Zhai S, Gardiner F, Neeman T, Jones B, Gawarikar Y. The Cost-Effectiveness of a Stroke Unit in Providing Enhanced Patient Outcomes in an Australian Teaching Hospital. Journal of stroke cerebrovascular diseases: the official journal of National Stroke Association. 2017;26(10):2362-8. doi:10.1016/j.jstrokecerebrovasdis.2017.05.025.

20. Drummond M, Barbieri M, Cook J, Glick HA, Lis J, Malik F, et al. Transferability of economic evaluations across jurisdictions: ISPOR Good Research Practices Task Force report. Value in health: the journal of the International Society for Pharmacoeconomics Outcomes Research. 2009;12(4):409-18. doi:10.1111/j.1524-4733.2008.00489.x.

21. Mahboub-Ahari A, Pourreza A, Sari AA, Rahimi Foroushani A, Heydari H. Stated time preferences for health: a systematic review and meta analysis of private and social discount rates. Journal of research in health sciences. 2014;14(3):181-6.

22. Central Bank of The Islamic Republic of Iran. Foreign Exchange Rates [May 31, 2021, Available from: https://www.cbi.ir/exrates/rates_en.aspx].

23. World Bank. PPP conversion factor [May 31. 2021, Available from: https://data.worldbank.org/].

24. Sandercock P, Berge E, Dennis M, Forbes J, Hand P, Kwan J, et al. A systematic review of the effectiveness, cost-effectiveness and barriers to implementation of thrombolytic and neuroprotective therapy for acute ischaemic stroke in the NHS. Health Technol Assess. 2002;6(26):1-112. doi:10.3310/hta6260.

25. Holmes M, Davis S, Simpson E. Alteplase for the treatment of acute ischaemic stroke: a NICE single technology appraisal; an evidence review group perspective. PharmacoEconomics. 2015;33(3):22533. doi:10.1007/s40273-014-0233-z.

26. Wardlaw JM, Lewis SC, Dennis MS, Counsell C, McDowall M. Is visible infarction on computed tomography associated with an adverse prognosis in acute ischemic stroke? Stroke. 1998;29(7):1315-9. doi:10.1161/01.str.29.7.1315.

27. Jørgensen HS, Kammersgaard LP, Nakayama H, Raaschou HO, Larsen K, Hübbe P, et al. Treatment and rehabilitation on a stroke unit improves 5-year survival. A community-based study. Stroke. 1999;30(5):930-3. doi:10.1161/01.str.30.5.930.

28. Marseille E, Larson B, Kazi DS, Kahn JG, Rosen S. Thresholds for the cost-effectiveness of interventions: alternative approaches. Bull World Health Organ. 2014;93:118-24. 
Figures

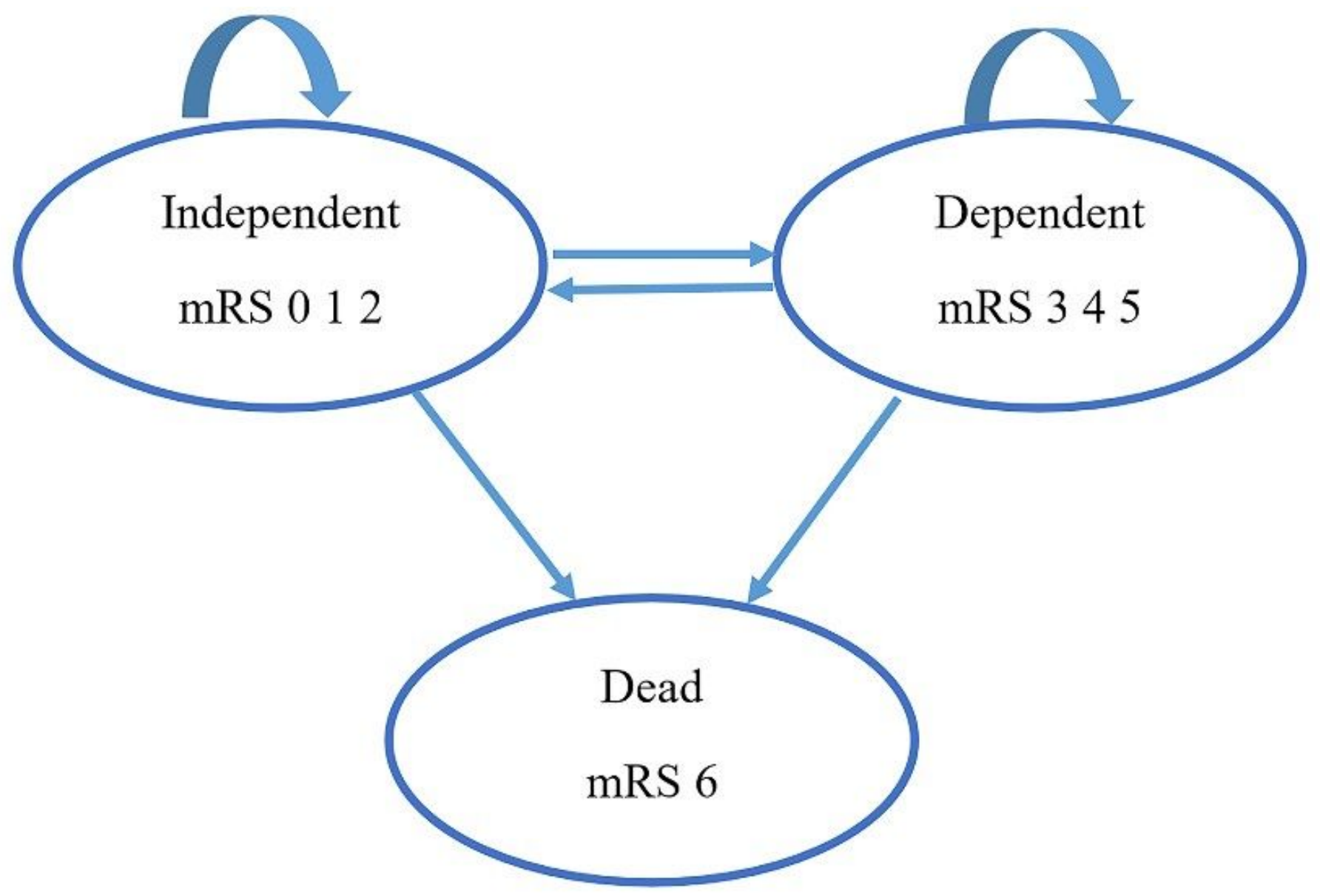

Figure 1

Markov decision analytic model for the stroke patients 


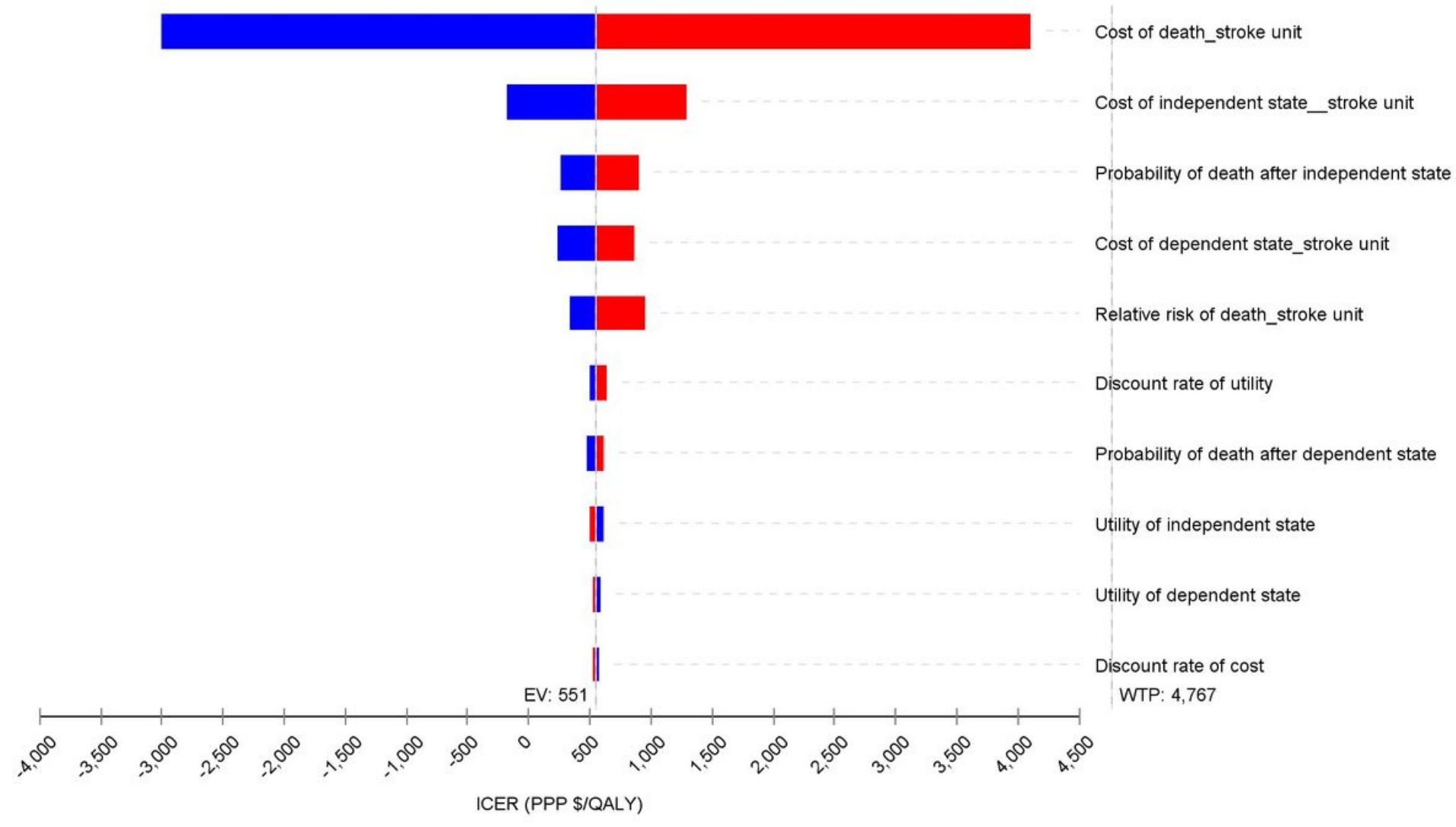

\section{Figure 2}

\section{Tornado chart for incremental cost per QALY}

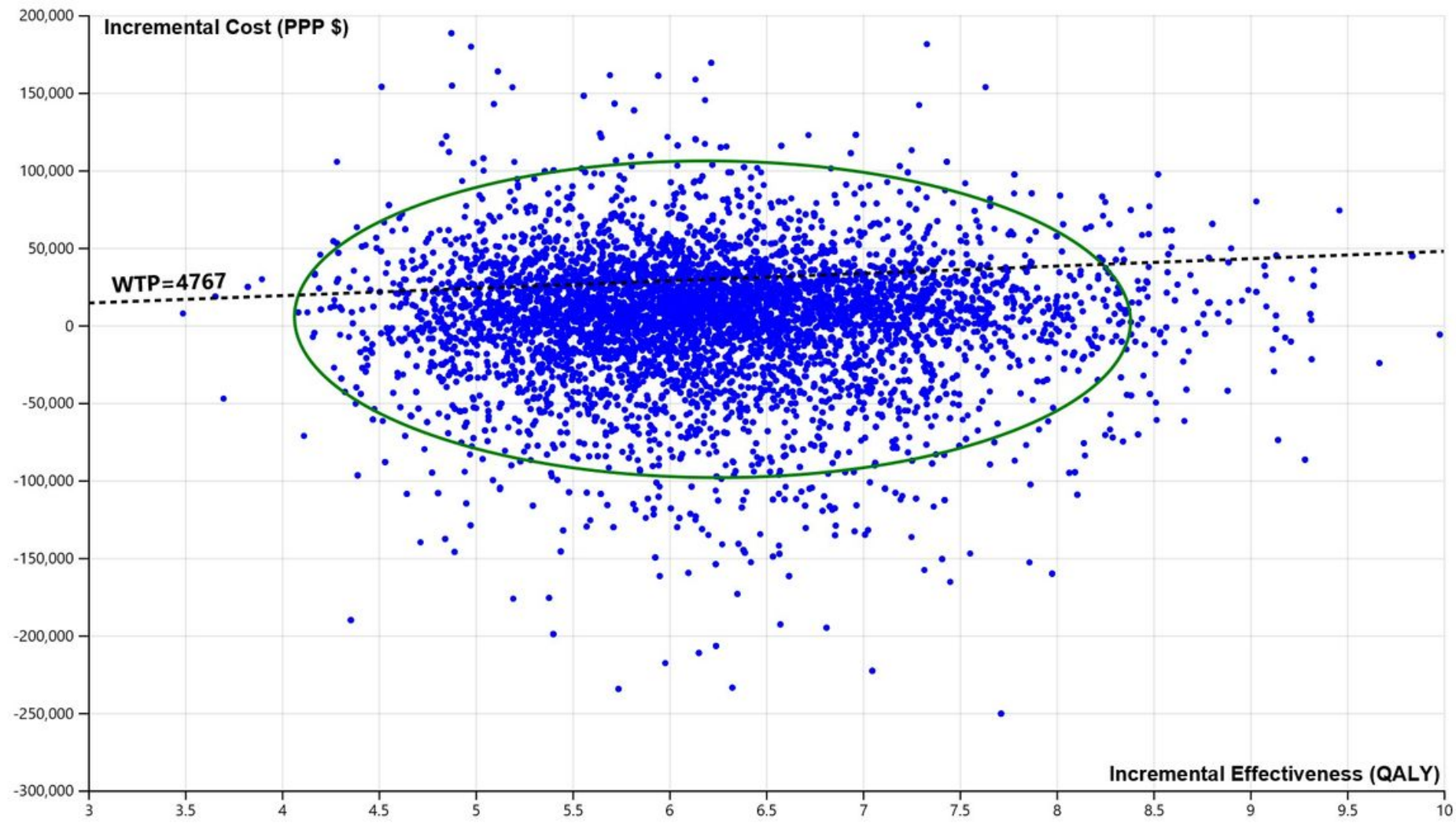




\section{Figure 3}

Incremental cost-effectiveness scatter plot for Stroke Unit compared Routine Treatment

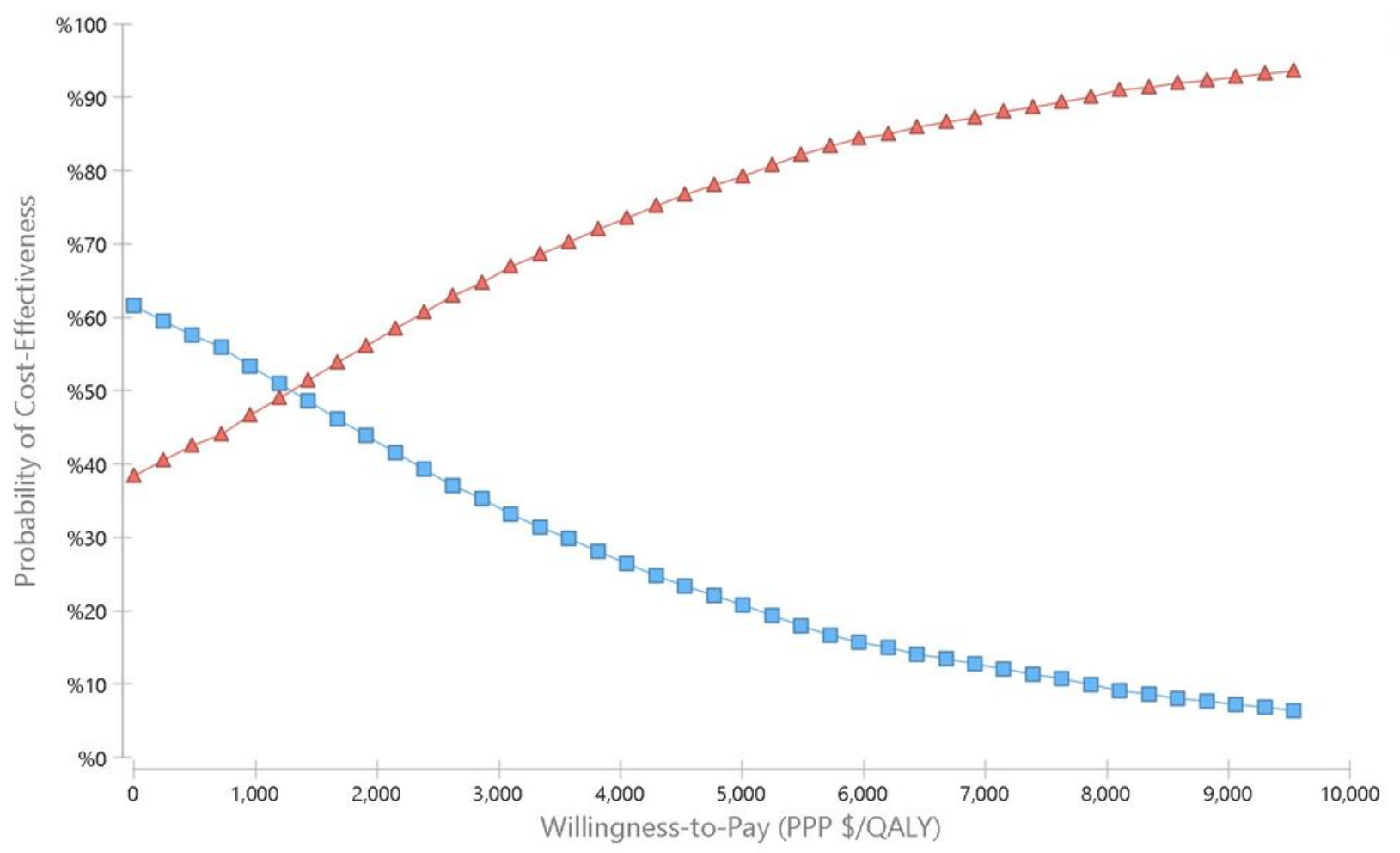

\section{Figure 4}

cost-effectiveness acceptability curve for Stroke Unit Versus Routine treatment 